\title{
Selection and Use of Mediation Testing Methods: Application in Management Sciences
}

\author{
Ghulam Dastgeer ${ }^{1}$, Atiq ur Rehman ${ }^{2}$, Muhammad Ali Asghar ${ }^{3}$
}

\begin{abstract}
This research article presents a comparative analysis of three major methods of mediation analysis i.e., Baron and Kenny, Sobel, Hayes indirect effect with bootstrap using PROCESS macro and Structural Equation Modeling (SEM). It discusses common issues associated with mediation analysis and common mistakes committed in the selection and application of methods and in the interpretation of results. In this article we have developed and tested a variety of models including simple mediation, parallel mediation, and serial/sequential mediation models. We have used a research model drawn from management field which includes two independent variables (i.e., organization justice and corporate social responsibility), two dependent variables (i.e., employee wellbeing and organization performance) and two mediating variables (i.e., organization trust and organization culture). The article illustrates that bootstrapping has an advantage over Baron and Kenny method and Sobel test. Besides, it has high statistical power and better control on type-I error. It produces better results even when data lacks the property of normal distribution. The article has many practical implications. More particularly for management researchers, it provides an in-depth understanding of how to correctly conduct mediation analysis.
\end{abstract}

Keywords: Mediation analysis, Baron and Kenny, Sobel, Hayes, bootstrapping, SEM

\section{Introduction}

\subsection{Background}

There is a growing trend of the use of mediation analysis in psychology, management, marketing, human resource management studies (Hertzog, 2018; Roberts, Scammacca \& Roberts, 2018; Tate, 2015; Preacher, Rucker, \& Hayes, 2007). Rucker, Preacher, Tormala and Petty (2011) reported the use of mediation in 59 percent and 65 percent of the articles published in the Journal of Personality and Social Psychology

1 Assistant Professor, University of Hail, Hail City, Saudi Arabia. Email: dr.g.dastgeer@gmail.com 2 CEO, Asian Center for Organization Development, Islamabad, Pakistan. Email: atiq787@gmail.com

3 Lecturer, PhD Scholar, International Islamic University, Islamabad, Pakistan. Email: aliasghar@iiu.edu.pk

\section{ARTICLE HISTORY}

05 Sep, 2018 Submission Received

28 Nov, 2018 First Review

04 Dec, 2019 Second Review

22 Feb, 2020 Accepted 
(JPSP) and Personality and Social Psychology Bulletin, respectively, published from 2005 to 2009.

What is a mediator? A mediator is a variable that accounts for a part of relation between an independent variable, hereafter denoted as ' $X$ ', and a dependent variable, hereafter denoted as ' $\mathrm{Y}$ ' (Baron and Kenny, 1986). In view of this it is considered as a transmitter of the effect of X on Y (Stone-Romero \& Rosopa, 2004). Baron and Kenny (1986) go one step ahead by suggesting that a mediator refers to "how or why such effects occur".

What is the use of a mediator? Inclusion of a mediator helps in yielding a more precise description of relationship between a predictor and a criterion (Bennett, 2000). Choi (2014) believes that mediation aids in the identification of missing link between any two variables that could potentially play an important role. Hence, understanding of such relationships can provide useful insights to management practitioners and researchers. Testing of theories related to process also involves the use of mediation tests (Rucker et al., 2011).

However, there are many gaps in the existing literature on the mediation tests. First, overuse and misuse of mediation analysis is common (Tate, 2015). Second, literature on clear description and use of mediation testing methods are scarce, especially young researchers from management and social sciences got confused in comprehending highly complicated statistical literature on mediation analysis. Zhao, Lynch Jr. \& Chen (2010) have highlighted non-technical flaws of Baron and Kenny (1986) method and provided illustration of its use. However, literature covering such dimensions (non-technical flaws and illustrations) of the other major methods i.e., Sobel, PROCESS and SEM-based mediation methods is rare. Third, literature on the comparative analysis of these methods is very limited. This article attempts to bridge up these gaps. The researchers MacKinnon, Lockwood, Hoffman, West and Sheets (2002) have identified 14 different methods to test mediation.

The basic objectives of the study are: 1) to discuss issues associated with the selection and application of the three major mediation analysis methods; 2) to illustrate how to apply these methods and interpret their results; and 3) present a comparative analysis of the three methods. The followings are the key contributions of this article. First, the paper identifies basic assumptions for testing mediation and suggests key considerations that must be kept in view before applying mediation tests. Second, it presents description, illustration and weaknesses of the three major methods of mediation. Third, it suggests the situations in which a specific method can work and situations it does not work. Fourth, it presents a way of drawing inferences from the results. 


\section{Conceptual and Methodological Considerations}

\subsection{Understanding the links in mediation}

In mediation analysis we take into consideration three types of effects i.e. total effect, direct effect and the indirect effect of Independent variable (X) on dependent variable $(Y)$ (Hayes, 2009). Total effect is the sum of direct effect and the indirect effect. Total effect is usually denoted by c (without inclusion of any mediator, see Figure $1 \mathrm{~A}$ ). The direct effect of $\mathrm{X}$ on $\mathrm{Y}$ is denoted by c' - it is measured only after inclusion of a mediator (see Figure 1B).

There are two methods to determine the indirect effect:

- Method 1: multiply the "effect of X on M" (its coefficient is denoted by 'a') with the "effect of M on Y" (its coefficient is denoted by ' $b$ '). Hence, the indirect effect $=a b$

- Method 2: Simply subtract direct effect (coefficient c') from total effect (coefficient c).

The mediation paths are expressed as follows:

- $\quad$ Total effect $(c)=c^{\prime}+a b$

- Indirect effect $(\mathrm{ab})=\mathrm{c}-\mathrm{c}^{\prime}$

- $\quad$ Direct effect $\left(c^{\prime}\right)=c-a b$

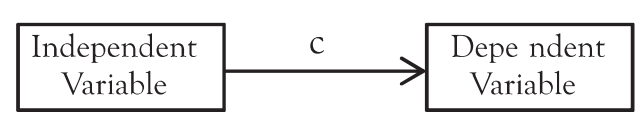

Fig: A

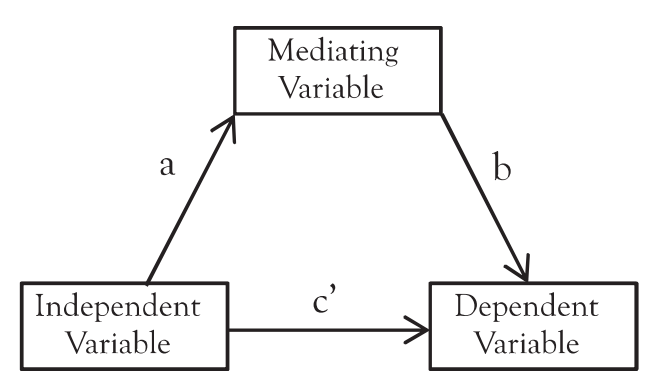

Fig: B

Figure 1: Total, Direct and Indirect Effect of X on Y

\subsection{Theoretical framework and hypotheses}

The basic theoretical framework used in this study (see Figure 2) is comprised of two independent variables (Organizational Justice and Corporate Social Responsibility), two mediating variables (Organizational Trust and Organizational Culture) 
and two dependent variables (Employee Wellbeing and Organizational Performance). Discussion on the theoretical foundations of the theoretical framework of the present study is beyond the scope of this article. However, it is crucial to acknowledge the earlier studies which provided foundation to the theoretical framework of the present study. The framework is an extension of the framework developed by Yu \& Choi (2014). They hypothesized that perceived corporate social responsibility (CSR) has positive and significant effect on organizational trust (OT), employee well-being (OW) and organizational performance (OP). Yu \& Choi (2014) also hypothesized that OT partially mediates the effect of CSR on OW and OP. They suggested that future studies should also test the mediation effect of culture between CSR and organizational performance.

Another non-traditional variable that affects the OT is the organizational justice (OJ). For example, Chen, et al. (2015) found that organizational justice (OJ) positively affects OT.

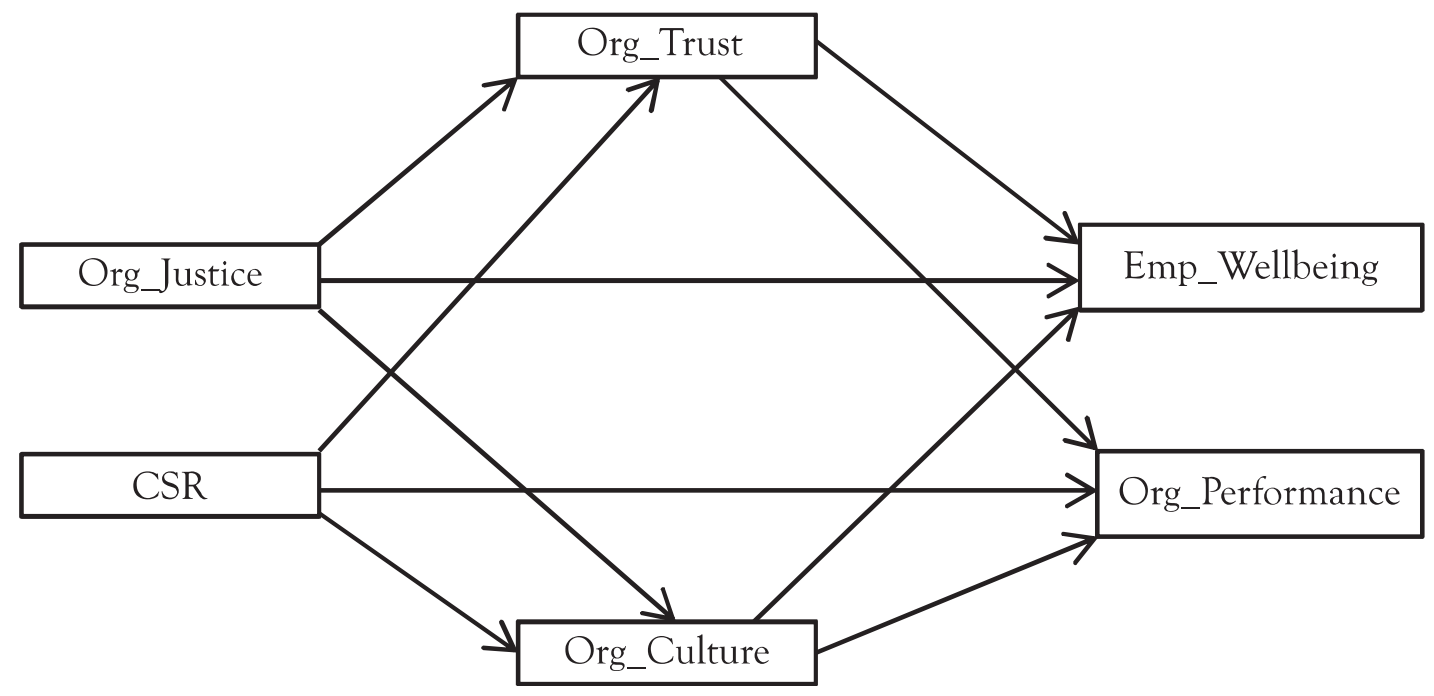

Figure 2: Hypothesized Model of The Current Study

The theoretical framework presented in Figure 2, depicts all theorized meditated relationships between independent and dependent variables. In the given model based on direct effect, we can test four different mediated relations, hypothesized in Table 1.

Table 1: Hypothesized Mediated Relationships Between IVs and DVs

\begin{tabular}{|c|c|}
\hline H1 & $\begin{array}{c}\text { Organization culture mediates the relationship between organization Justice and employee } \\
\text { wellbeing }\end{array}$ \\
\hline H2 & $\begin{array}{c}\text { Organization trust mediates the relationship between organization Justice and employee } \\
\text { wellbeing }\end{array}$ \\
\hline H3 & Organization trust mediates the relationship between CSR and Organization performance \\
\hline H4 & Organization culture mediates the relationship CSR and Organization performance \\
\hline
\end{tabular}




\subsection{Sampling design}

To statistically test hypotheses data were collected from banking organizations operating in Rawalpindi/Islamabad using random sampling technique. Achieved sample size $(\mathrm{N})$ is 176 managerial level employees. Gender composition is $76 \%$ male and $24 \%$ female (figures round of).

\section{Testing Mediation}

\subsection{Simple mediation using Baron and Kenny (1986) method (using AMOS)}

\subsubsection{Description}

Baron and Kenny (1986) method is the most commonly used method of testing mediation. According to Social Citation Index it is also called as a classical test of mediation. It has remained a popular method of testing mediation for over two decades. In majority of the studies, Baron \& Kenny (1986) method has been used (Rucker, Preacher, Tormala \& Petty, 2011; MacKinnon, Fairchild \& Fritz, 2007).

Baron and Kenny (1986) method employs hierarchical multiple regression (HMR). It requires that three conditions must be satisfied before testing mediation which include:

- There is a significant causal relation between $\mathrm{X}$ and $\mathrm{Y}$

Equation 1: $\mathrm{Y}=\mathrm{c} 0+\mathrm{cX}+\mathrm{e} 1$

- There is a significant causal relation between X and M

$\circ \quad$ Equation 2: $\mathrm{M}=\mathrm{c} 0+\mathrm{aX}+\mathrm{e} 2$

- There is a significant causal relation between $\mathrm{M}$ and $\mathrm{Y}$

Equation 3: $\mathrm{Y}=\mathrm{c} 0+\mathrm{bM}+\mathrm{e} 3$

If one or more of the above conditions are not met, there is no mediation. Hence, there is no need to proceed further. However, if all three conditions are found fulfilled, then the mediator is controlled and the causal effect of X on Y is checked. Lucia-Palacios, Bordonaba-Juste, Polo-Redondo \& Grunhagen (2014) used two steps: 1) testing relationship between $X$ and $Y$ without mediator; and 2) adding mediator and re-running the test.

Equation 4: $Y=a+c^{\prime} X+d M+e 4$ 
After inclusion of mediator (see equation 4), if $\mathrm{X}$ is no longer significant, there is full mediation, as suggested by Stone-Romero and Rosopa (2004). Baron and Kenny (1986) say, "When path c is reduced to zero, we have strong evidence for a single, dominant mediator. If the residual Path $\mathrm{c}$ is not zero, this indicates the operation of multiple mediating factors." But if X is still significant but its coefficient has declined, then there is partial mediation. However, a point of caution is that absence of the significance of X should be interpreted as full mediation only if it is supported by theory (Rucker, Preacher, Tormala \& Petty, 2011).

\subsubsection{Illustration}

First, the total effect of Organization Justice $(\mathrm{X})$ on Employee Wellbeing $(\mathrm{Y})$ was estimated (hypothesis H1). It was found to be $0.28 p<0.001$, which fulfills the first condition of running a mediation analysis (Figure 3; Table 2).

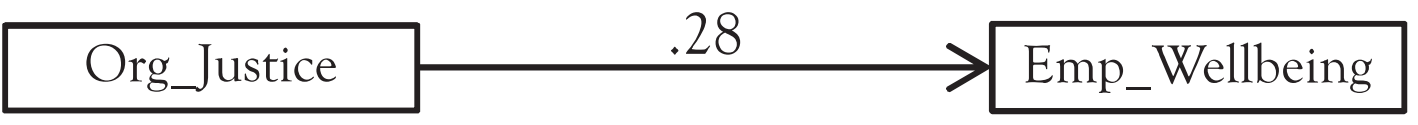

Figure 3: The Effect of Org_Justice (i.e. X) on Emp_Wellbeing (i.e. Y)

Table 2: Regression Weights: (Group number 1 - Default model)

\begin{tabular}{|c|c|c|c|c|c|c|}
\hline \multicolumn{3}{|c|}{ Relationship } & $\begin{array}{c}\text { Unstandardized } \\
\text { Beta }\end{array}$ & $\begin{array}{c}\text { Standardized } \\
\text { Beta }\end{array}$ & S.E & P \\
\hline $\begin{array}{c}\text { Emp_Well- } \\
\text { being }\end{array}$ & $<$ & Org_Justice & .241 & .28 & .069 & 0.00 \\
\hline
\end{tabular}

In the second step of Baron and Kenny (1986), we added a mediator i.e., organizational trust (OT) between X and Y. Results given in Figure 4 and Table 3 show that: 1 ) relationship between $\mathrm{X}$ and $\mathrm{M}$ (a path) is significant $(0.37, \mathrm{P}<0.001)$; 2) relationship between $\mathrm{M}$ to $\mathrm{Y}(\mathrm{b}$ path) is also significant $(0.38, \mathrm{P}<0.001)$; 3$)$ direct effect $\left(\mathrm{c}^{\prime}\right)$ path which is non-significant $(0.13, \mathrm{p}=0.09)$.

Comparing Table 2 with Table 3 shows that the previously significant relationship between X and Y $(.28, p=0.00)$ is no more significant $(0.13, p=.09$ in Table 3$)$. Summary is presented in Table 4. It implies that addition of M (organizational trust) has turned the relationship insignificant. Hence, we conclude that organizational trust fully mediates the relationship between organizational justice and employee wellbeing.

\subsubsection{Weaknesses of Baron and Kenny method}

Many scholars (e.g. Rucker, Preacher, Tormala \& Petty, 2011; Zhao, Lynch Jr. \& Chen, 2010; Hayes, 2009) have identified limitations of the approach of the Baron 


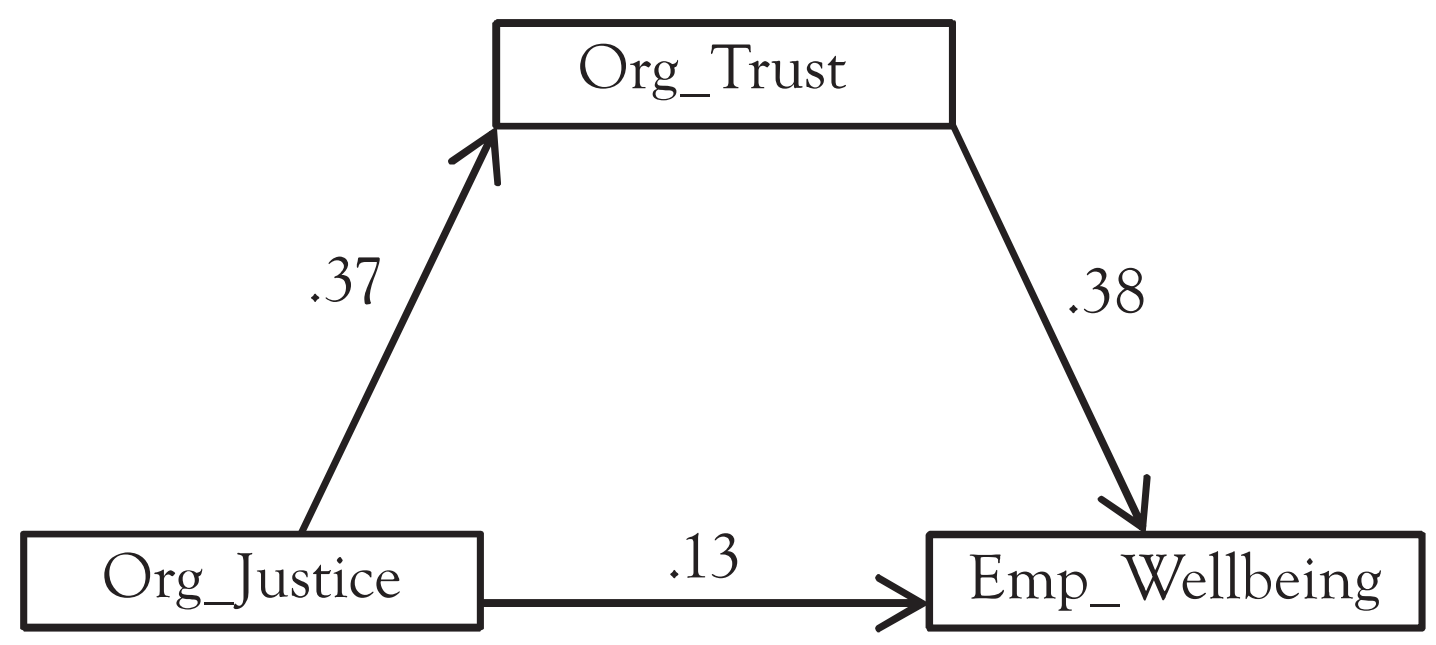

Figure 4: Mediation of Organizational Between OJ on EW

Table 3: Regression Weights - X, M and $\mathrm{Y}$

\begin{tabular}{|c|c|c|c|c|c|c|}
\hline $\begin{array}{c}\text { Relation- } \\
\text { ships }\end{array}$ & $\leftarrow$ & $\begin{array}{c}\text { Estimate } \\
\text { (unstan- } \\
\text { dardized) }\end{array}$ & $\begin{array}{c}\text { Estimate } \\
\text { (Standard- } \\
\text { ized }\end{array}$ & P value & $\begin{array}{c}\text { Standard } \\
\text { Error (S.E) }\end{array}$ \\
\hline $\begin{array}{c}\text { Org_Trust } \\
(\mathrm{M})\end{array}$ & $\leftarrow$ & .262 & .375 & 0.00 & .053 \\
\hline $\begin{array}{c}\text { Emp_Well- } \\
\text { being (Y) }\end{array}$ & $\leftarrow$ & $\begin{array}{c}\text { Org_Trust } \\
(\mathrm{M})\end{array}$ & .481 & .384 & 0.00 & .098 \\
\hline $\begin{array}{c}\text { Emp_Well- } \\
\text { being (Y) }\end{array}$ & $\leftarrow$ & $\begin{array}{c}\text { Org_Justice } \\
(\mathrm{X})\end{array}$ & .115 & .131 & 0.095 & .069 \\
\hline
\end{tabular}

and Kenny method of mediation. First, overemphasis of the effect between X and Y before and after controlling the $\mathrm{M}$ could be misleading. A significant indirect effect (a $\mathrm{x}$ b) can be detected even when "c" is not statistically significant (Rucker et al., 2011; Zhao et al., 2010). Critics argue that because X might have a stronger and statistically

Table 4: Identifying Mediation Effect with Baron and Kenny (1986) Rules

\begin{tabular}{|c|c|c|c|c|c|}
\hline \multirow[t]{2}{*}{ Relationship } & \multicolumn{2}{|c|}{ Total Effect (C path) } & \multicolumn{2}{|c|}{ Direct Effect (C' path) } & \multirow{2}{*}{$\begin{array}{c}\text { Mediation } \\
\text { Result }\end{array}$} \\
\hline & Beta & $\mathrm{P}$ & Beta & $\mathrm{P}$ & \\
\hline $\begin{array}{l}\text { Org_Justice =IV Emp_Well- } \\
\text { being }=\text { DV Org_Trust }=\text { Med }\end{array}$ & .28 & .000 & .13 & .09 & $\begin{array}{l}\text { Full Media- } \\
\text { tion }\end{array}$ \\
\hline
\end{tabular}


significant impact on M (a path) than on Y (c path) that means there could be a stronger indirect effect than a total effect. Second, mediation testing involving the use of regression analysis can produce measurement error in the mediator score (Hopwood, 2007). Third, error terms might correlate and lead to violation of underlying assumptions, which would make coefficients biased and inconsistent (Shaver, 2005). Fourth, the presence of mediation does not necessarily require direct path " $c$ " (figure 1a) to be significant (Rucker et al. 2011; Shrout \& Bolger, 2002). Rucker et al. (2011) gave statistical evidence for the presence of significant indirect effect $(\mathrm{a} \times \mathrm{b})$ even when total and direct effects are non-significant. Hence, the first condition of the Baron and Kenny (1986) becomes questionable and researcher can establish indirect effect "a x b" despite no total effect "c" (Zhao et al., 2010). Fifth, it has only a modest ability to provide for inferences of partial or complete mediation (Stone-Romero \& Rosopa, 2004). Claim of full mediation in Baron and Kenny method means that a researcher cannot add additional indirect effects if direct effect c' is significant, whereas Rucker et al. (2011) proved that additional indirect effects (a highly reliable $\mathrm{M}$ variable) can be detected (added to equation) even when total effect $c$ ' is statistically non-significant. Further they claimed that addition of this mediating variable would increase power to regression weight associated with it (both indirect effects "a \& b") but would do nothing for total effect (c path). Besides, with a reasonably moderate sample size, a researcher would more likely achieve full mediation than partial because direct effect $c^{\prime}$ is more easily rendered non-significant. Moreover if the researcher has very small total effect with a $\mathrm{p}$ value of 0.05 will likely to have full mediation because $\mathrm{p}$ value of direct effect c' will be greater than 0.05 after introducing $M$ variable. That's why according to Rucker et al. (2011) and Zhao et al. (2010) there is no need to use words like partial or full/complete mediation if you are trying to find an indirect effect (a x b). Hence the claims about the Baron and Kenny method regarding: i) full or partial mediation and ii) justification of mediation based on size and significant effect of direct effect c' is void and a serious threat to theory development as it might cause researchers to mis-theorize relations that are existing in the data i.e. full mediation does not allow researchers to test additional mediating pathways in model. Whereas there is always a possibility of additional mediation (guided by theory) even if 'c' is non-significant and one cannot claims to have established complete mediation (Rucker et al., 2011; Zhao et al., 2010). Sixth, if any one or both of the endogenous variables i.e. $\mathrm{M}$ and $\mathrm{Y}$ are binary, then simple regression will not work (MacKinnon \& Dwyer, 1993). Seventh, Baron \& Kenny method is criticized for lower statistical power to detect total and direct effects than the power to detect the indirect path "a x b” (Rucker et al. 2011; MacKinnon et al., 2002). Rucker et al. (2011) and Zhao et al., (2010) recommended one and only requirement to justify mediation by examining the magnitude of indirect ( $\mathrm{a} \times \mathrm{b})$ only. That means significant or non-significant indirect effect (c') does not necessarily mean existence or nonexistence of mediation. Eighth, 
the method is valid for a situation which involves one way mediated relationship (Sanders, 2007). Ninth and the last, if data is lacking property of normal distribution, findings might be misleading.

\subsection{Sobel test of Ho: ab product $=0$}

\subsubsection{Description}

Sobel test examines whether the entire pathway from $\mathrm{X}$ to $\mathrm{Y}$ via $\mathrm{M}$ is reliable, as a package. It has many similarities with Baron and Kenny (1986) method. It also involves the use of hierarchical regression method (Da Silveira and Arkader, 2007). However, it has been used by relatively less number of studies.

Why is Sobel test needed? Sobel (1982) argues that

"Thus sociologists (and researchers in many other disciplines as well) typically treat the indirect effects they calculate as parameter values and formulate inferences without asking whether the effect itself is statistically significant." (p. 291)

It may be noted that Sobel Test is not a substitute of Baron \& Kenny (1986) test. It rather compliments the later (Rucker et al., 2011).

This test works well in a situation when full data are not available, and the researcher has only results of regression analysis ( $\mathrm{M} \square \mathrm{X}$; and $\mathrm{Y} \square \mathrm{M})$.

Following steps are involved in using Sobel Test:

- Step 1: calculate coefficient of X for M (i.e. a) and its standard error (sa)

- Step 2: calculate coefficient of M for Y (i.e. b) and its standard error (sb)

- Step 3: Use values of a, b, sa and sb in Sobel Calculator (available at: http://quantpsy.org/sobel/sobel.htm). The values are put in the Input column (see figure5)

Table 5: Sobel Testing Calculator

\begin{tabular}{|c|c|c|c|c|}
\hline Input & & t-statistics: & Std. Error: & p-value \\
\hline $\mathrm{a}$ & Sobel test & & & \\
\hline $\mathrm{b}$ & Aroian test & & & \\
\hline $\mathrm{s}^{\mathrm{a}}$ & Goodman test: & & & \\
\hline $\mathrm{s}^{\mathrm{b}}$ & Reset all & Calculate & & \\
\hline
\end{tabular}


Alternatively, $t$ statistic of each of the above mentioned coefficients can be used to run the test. In order to interpret results of Sobel test, we look at p-values given in the Sobel table (see Table 6). If p-value is 0.05 or below, we conclude that mediation is statistically significant.

\subsubsection{Illustration}

We performed the Sobel (1982) test for the same data we used in testing mediation with Baron and Kenny (1986) method. As described earlier Sobel test is used to measure the significance level ( $\mathrm{p}$ value only) of indirect effect which is product of a, $\mathrm{b}$ path (i.e. ab). First to find out the total indirect beta effect we manually multiply both indirect unstandardized beta effects that are from $\mathrm{X}$ to $\mathrm{M}$ is 0.262 and from $\mathrm{M}$ to $\mathrm{Y}$ is 0.481 . The product of both coefficients is $\left(.262^{*} .481=.126\right)$. To run Sobel test of direct effect significance we used online Sobel calculator (http://quantpsy. org/sobel/sobel.htm). Where we need the coefficients and standard errors (SE) of indirect effects (i.e. $M \leftarrow X$; and $Y \leftarrow M$ ). Here again, $X=$ justice, $M=$ trust and $Y=$ wellbeing. A detailed discuss is given below.

As the Sobel test involves the use of inputs generated by the Baron and Kenney (1986) Method. Table 3 contains all required values i.e. a (coefficient of $\mathrm{M} \leftarrow \mathrm{X}$ ), b (coefficient of $\mathrm{Y} \leftarrow \mathrm{M}$ ), sa (standard error of a) and sb (standard error of $\mathrm{b}$ ). These inputs were entered into the Sobel test calculator. Input and output of the Sobel test are presented in figure 5.

\begin{tabular}{|c|c|c|c|c|}
\hline Input: & & Test statistic: & Std. Error: & $p$-value: \\
\hline a. 262 & Sobel test: & 3.48298544 & 0.03618218 & 0.00049586 \\
\hline b. .481 & Aroian test: & 3.44764381 & 0.03655308 & 0.0005655 \\
\hline$s_{\mathrm{a}} .053$ & Goodman test: & 3.51943669 & 0.03580743 & 0.00043246 \\
\hline$s_{\mathrm{b}} .098$ & Reset all & & Calculate & \\
\hline
\end{tabular}

Figure 5: Sobel Test Results Using Online Calculator

Figure 5 depicts results of Sobel test. Ignoring the Aroian and Goodman test, the first row (Soble test) contains the p value of ab (product of indirect effect) which is $0.0005(<0.001)$ that is highly significant and confirming that the total indirect effect is significant. It implies that the organizational trust fully mediates the relationship between organizational justice and employee wellbeing.

\subsubsection{Weaknesses of Sobel test}

Much of the criticism against Baron and Kenny (1986) method is valid for the 
Sobel test too. However, there are some additional issues too:

- Sobel test works well only in case where there is a large sample size and the sampling of indirect effect holds the properties of normal distribution (Rucker, Preacher, Tormala \& Petty, 2011).

- The Sobel test inclines to produce an incorrect approximation to the true confidence interval of the mediated effect (MacKinnon, Warsi \& Dwyer, 1995).

- The Sobel test is inadequate to show that the effect of X on $\mathrm{Y}$ is reduced in size when $\mathrm{M}$ is added to the model (Preacher \& Hayes, 2008).

- Sobel test is low in power compared to a bootstrap test (Zhao et al., 2010)

\subsection{Bootstrapped confidence interval for indirect effect ( $\mathrm{a} X \mathrm{~b})$ using PROCESS macro (Hayes, 2012).}

\subsubsection{Description}

Preacher and Hayes (2008) state that bootstrapping "is a computationally intensive method that involves repeatedly sampling from the data set and estimating the indirect effect in each resampled data set". Bootstrapping technique has many advantages:

- It has the capability to test a multi-mediation model (Preacher and Hayes, 2008).

- It is preferable over Sobel Test and causal method of mediation testing because it has higher power and better control over Type-I error (Preacher and Hayes, 2008).

- It does not require the data to be perfect normally distributed (Preacher and Hayes, 2008).

To estimate the bootstrapped confidence interval for indirect effect, the Process macro developed by Hayes (2012) is used. It runs as "adds-on" in SPSS. Results generated through the PROCESS are contained four sub-tables:

- Sub-table 1: It shows the effect of X on M (“a” path).

- Sub-table 2: It shows the effect of X and M on Y (both X and M are included as independent variables; "b and c' paths").

- Sub-table 3: It shows the effect of X on Y (without inclusion of M; "c" path).

- Sub-table 4: It shows

- Total effect of $\mathrm{X}$ on $\mathrm{Y}$ [taken from sub-table 3]. If $\mathrm{p} \leq 0.05$, then total effect is 
statistically significant.

- Direct effect of X on Y [taken from sub-table 2]. If $\mathrm{p} \leq 0.05$, then direct effect is statistically significant.

O Indirect effect of X on Y (total effect - direct effect). If signs of the lower level confidence interval (BootLLCI) and upper level confidence interval (Boot$\mathrm{ULCI}$ ) are different (one is positive and other is negative), then the indirect effect is not statistically different from zero. In other words, the indirect effect is statistically insignificant. But if signs of both are same (either both are negative or both are positive) then the indirect effect is statistically significant (Hayes, 2013, p. 103).

- Normal theory tests. This is also known as the product of coefficients approach to interference or Sobel test. If $\mathrm{p} \leq 0.05$, then we infer that the indirect effect is statistically significant (Hayes, 2013, p. 103).

\subsubsection{Illustration}

Using Process macro in SPSS we followed the step by step process to produce results. Where using model number 4 we entered organization justice in the independent variable box, Employee wellbeing in the outcome variable box and organizational trust in M variable box. While using the PROCESS taking 2000 sample bootstrap with confidence level at 95\%.

The PROCESS runs the mediation analysis in 4 steps/models that are as following.

Step 1: causal relationship between X and Y (c path)

Step 2: causal relationship between $\mathrm{X}$ and $\mathrm{M}$ (a path)

Step 3 causal relationships where $\mathrm{X}$ and $\mathrm{M}$ both are regressed on $\mathrm{Y}$ (b and c' paths).

Step 4: identification of total, direct, and indirect paths with $\mathrm{p} /$ confidence intervals.

Following the above mentioned steps, the PROCESS generated results presented in Table 6.

Results given in Table 6 indicate that: 1 ) the effect of X (i.e. organization justice) on Y (i.e. Emp_wellbeing), ignoring the role of mediator, is significant, $b=.26, t=$ $14.02, p=<.001 ; 2$ ) the effect of $\mathrm{X}$ (i.e. Org_justice) on M (i.e. Org_trust), is also significant, $\mathrm{b}=.26, \mathrm{t}=4.93, \mathrm{p}=<.001 ; 3$ ) the effect of $\mathrm{M}$ (i.e. Org_trust) on Y (i.e. Emp_wellbeing), controlling for Organization Justice $(\mathrm{X})$, is significant, $\mathrm{b}=.48, \mathrm{t}=$ 


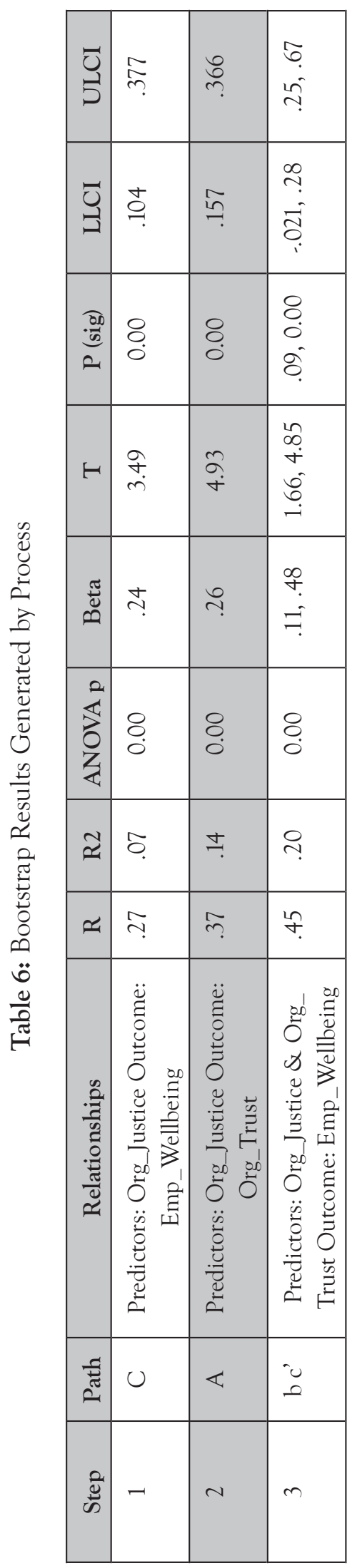


4.85, $\mathrm{p}=0.00$ and controlling for $\mathrm{M}, \mathrm{X}$ is no longer a significant predictor of $\mathrm{Y}, \mathrm{b}=$ $.11, \mathrm{t}=1.66, \mathrm{p}=.09$. It shows that mediating effect is there.

The PROCESS also produced results for all paths (total, direct, indirect) separately (See Table 7). The final justification of mediation effect in bootstrap technique depends upon the beta coefficient and the p value of indirect effect. Table 8 indicates that the indirect effect beta weight is .125 and the indirect procedure also provides a $95 \%$ confidence interval (CI) for the value of the indirect effect. The LICI is .05 and the ULCI is .23. Since zero does not fall between these two values, the null hypothesis that $\mathrm{ab}=0$ can be rejected. In other words, there is a remote chance that the indirect effect might not exist.

Table 7: Total, Direct and Indirect Effects Results Generated by Process

\begin{tabular}{|c|c|c|c|c|c|c|}
\hline & Beta & S.E & T & P & LLCI & ULCI \\
\hline Total Effect & .24 & .68 & 3.49 & .000 & .104 & .373 \\
\hline $\begin{array}{c}\text { Direct } \\
\text { Effect }\end{array}$ & .11 & .06 & 1.66 & .09 &. .021 & .252 \\
\hline $\begin{array}{c}\text { Indirect } \\
\text { Effect }\end{array}$ & .125 & .04 & - & - & .0 & \\
\hline
\end{tabular}

A Sobel test was conducted using special options available in the Process. Results are shown in Table 8. It shows that there is full mediation in the model $(z=3.42, p=$ .000). In other words, Org_trust fully mediates the relationship between Organization Justice and Emp_Wellbeing.

Table 8: Sobel Normal Theory Test for Indirect Effect.

\begin{tabular}{|c|c|c|c|}
\hline Effect & S.E & $\mathrm{Z}$ & $\mathrm{P}$ \\
\hline .125 & .036 & 3.42 & .000 \\
\hline
\end{tabular}

\subsubsection{Weaknesses}

PROCESS can run only pre-specified 72 different types of mediation / moderation models. Another limitation is that in all those 72 models we can use only one $\mathrm{X}$ and one $\mathrm{Y}$.

\subsection{Mediation with bootstrap technique of indirect effect $(\mathrm{ab})$ using AMOS}




\subsubsection{Description}

Most structural equation modeling (SEM) software provide bootstrapping technique to test mediation effect. These programs provide bootstrapped confidence intervals and associated statistical significance tests for ab indirect paths.

\subsubsection{Illustration}

We employed AMOS (a co-variance based SEM application) to run mediation analysis by assigning the value of 2000 for bootstrap samples along with the biased corrected confidence interval at $95 \%$.

AMOS generated similar results for Path c, a, b, and c' (both standardized and unstandardized) as in case of Baron and Kenny method application. To obtain total indirect effect $(\mathrm{ab})$ and significance level we looked for sstandardized indirect effect, bootstrapped confidence intervals (CIs) and $\mathrm{p}$ value.

Table 9 shows that the indirect unstandardized effect (ab) between $\mathrm{X}$ and $\mathrm{Y}$ is 0.126. It also shows $95 \%$ CI results for the estimate of the standardized ab indirect effect (in this example, the effect of org_Justice (X) on Emp_Wellbeing (Y), mediated by Org_Trust (M). The LLCI and ULCI are .069 and .261. The result of a statistical significance test for $\mathrm{HO}: \mathrm{ab}=0$, using an error term derived from bootstrapping, is $\mathrm{p}=.000$.

Table 9: Standardized Indirect Effects (ab): AMOS output

\begin{tabular}{|c|c|c|c|c|c|}
\hline $\begin{array}{c}\text { Indirect Rela- } \\
\text { tionships }\end{array}$ & $\begin{array}{c}\text { Beta (Stan- } \\
\text { dardized) }\end{array}$ & $\begin{array}{c}\text { Beta (Unstan- } \\
\text { dardized) }\end{array}$ & $\mathrm{P}$ & $\begin{array}{c}\text { Standardized } \\
\text { Lower limit of } \\
95 \% \mathrm{CI}\end{array}$ & $\begin{array}{c}\text { Standardized } \\
\text { Upper limit of } \\
95 \% \text { CI }\end{array}$ \\
\hline $\begin{array}{c}\text { Org_Justice } \\
\text { (IV) Emp_- } \\
\text { Wellbeing } \\
\text { (DV) }\end{array}$ & .144 & .126 & 0.00 & .069 & .261 \\
\hline
\end{tabular}

Table 10 shows all paths i.e. total, direct and indirect effects using bootstrapped sample of 2000 at $95 \%$ CI. Again the final justification of mediation using such technique is based on the beta weight and the $\mathrm{p}$ value of indirect effect. Here the indirect effect is 0.144 and is significant at $\mathrm{p}<0.001$ justifying that Org_Trust mediates the relationship between Org_justice and Emp_wellbeing. 
Table 10: Results of Indirect Effect of IV on DV

\begin{tabular}{|c|c|c|c|c|c|c|c|}
\hline \multirow[t]{2}{*}{ Relationship } & \multicolumn{2}{|c|}{ Total Effect (C) } & \multicolumn{2}{|c|}{ Direct Effect (C') } & \multicolumn{2}{|c|}{ Indirect Effect (axb) } & \multirow{2}{*}{$\begin{array}{l}\text { Medi- } \\
\text { ation } \\
\text { Result }\end{array}$} \\
\hline & Beta & $\mathrm{P}$ & Beta & $\mathrm{P}$ & Beta & $\mathrm{P}$ & \\
\hline $\begin{array}{c}\text { Org_Justice =IV } \\
\text { Emp_Wellbeing } \\
\text { =DV Org_Trust= } \\
\text { Med }\end{array}$ & .28 & .000 & .13 & .096 & 0.144 & .000 & $\begin{array}{l}\text { Full Medi- } \\
\text { ation }\end{array}$ \\
\hline
\end{tabular}

\subsection{Testing a complicated mediation model}

As discussed earlier, SEM softwares such as AMOS can be used to test any complicated interdependent model (involving more than one mediation equations) where we can run parallel and sequential mediation or moderation in a single model without breaking it into parts. To test a complex mediation (number of mediation equations in a single model), we ran our previous model given in Figure 2 using AMOS software with bootstrap technique. There are two Xs (independent variables), two Y (dependent variables), and two Ms (mediators). And based on these relations we developed four mediation hypotheses (see Table 1).

To test mediation effect, we followed three steps. At step 1, we found out the total effect (c) i.e., to examine the effect of Xs on Ys, without including mediators. Figure 6 depicts the total effect with Xs and Ys. We also correlated the Xs. The correlated value between $\mathrm{Xs}$ is .58 and the impact of org_Justice is .28 $(\mathrm{P}<0.001)$ and employee wellbeing has .60 ( $\mathrm{p}<0.001)$. For detail, see Figure 6 and Table 11.

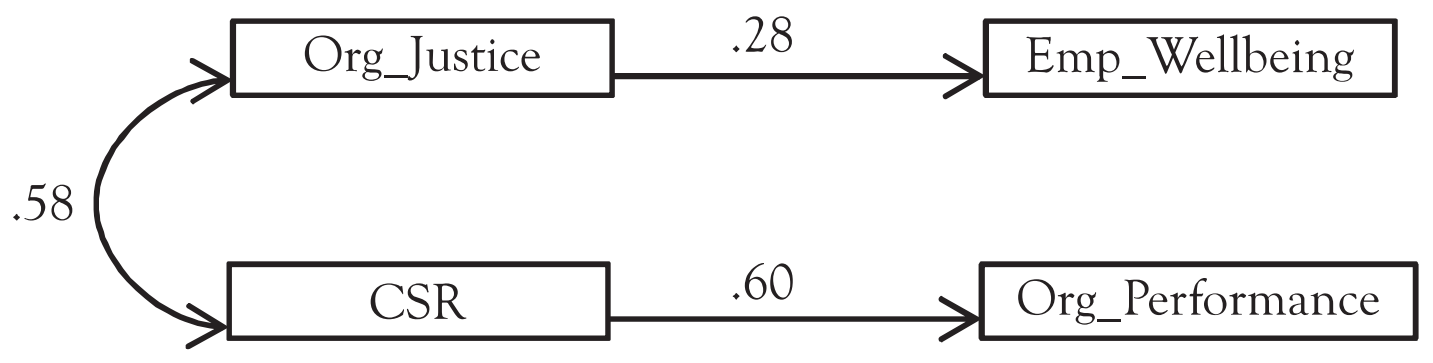

Figure 6: Testing Total Relations (c) Between IVs and DVs.

Table 11: Regression Weights: (Group number 1 - Default model)

\begin{tabular}{|c|c|c|c|c|c|c|}
\hline Relations & & & $\begin{array}{c}\text { Beta (unstan- } \\
\text { dardized) }\end{array}$ & $\begin{array}{c}\text { Beta (stan- } \\
\text { dardized) }\end{array}$ & S.E. & P \\
\hline Org_Performance & $\leftarrow$ & CSR & .595 & .28 & .065 & $* * *$ \\
\hline Emp_Wellbeing & $\leftarrow$ & Org_Justice & .241 & .60 & .069 & $* * *$ \\
\hline
\end{tabular}


At step 2, we included Ms (mediators) in the model (see Figure 7). Suppose we want to find out the indirect effect of org_justice on emp_wellbeing, we see that there are two indirect effects in this case: one through org_trust and the other through org_culture. We remove one indirect link so that we can find indirect effect on the other path. In Figure 7 you would see we have removed link between Org_Justice and Org_Trust so that we can find out the indirect effect of org_justice on Emp_Wellbeing through org_culture. Using bootstrap technique with AMOS we calculated total indirect effect (by combining both ways) from org_justice and emp_wellbeing. Figure 6 depicts that the path $A$ (from $X$ to $M$ ) is $.38(p<0.001)$ and path $B$ is (from $M$ to $\mathrm{Y})$ is $.52(\mathrm{P}<0.001)$. And the total indirect effect $(.38 \times .52)$ is .200 and significant at $\mathrm{p}<0.001$ justifying that org_culture mediate the relationship between org_justice and emp-wellbeing.

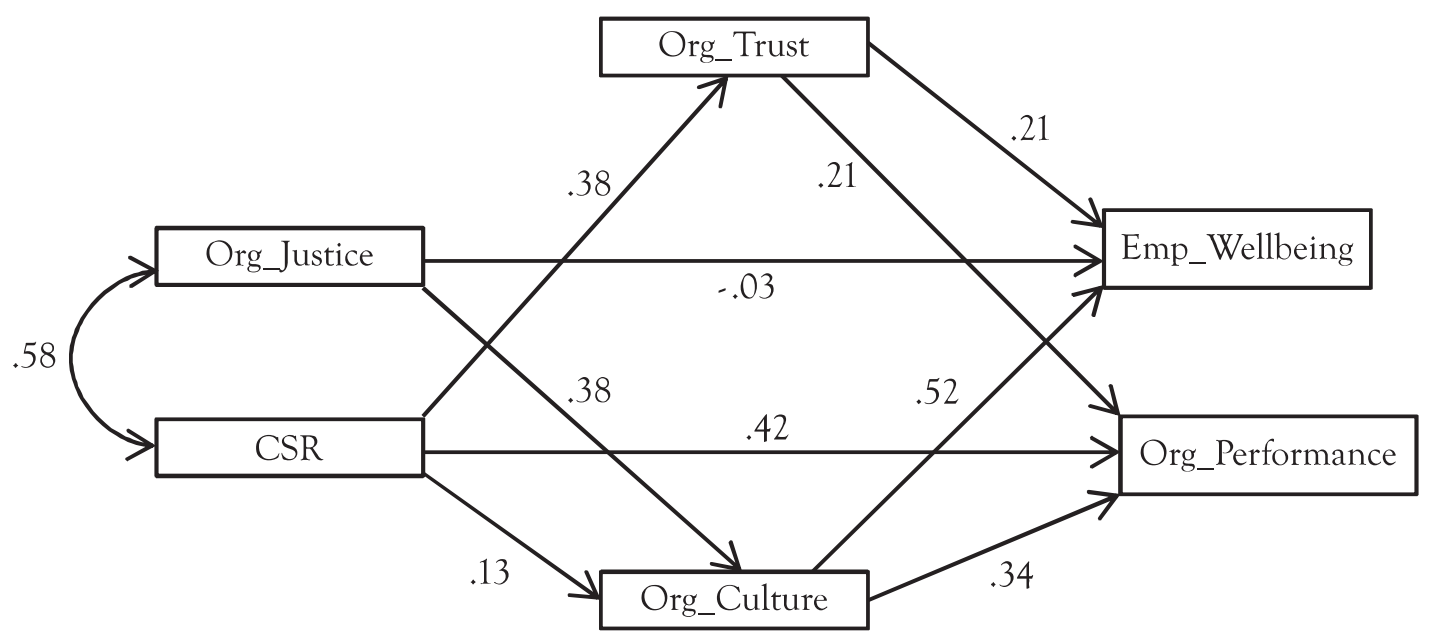

Figure 7: Testing Hypothesis Org_Culture Mediates the Relationship Between Org Justice and Emp_Wellbeing

Figure 8 depicts the testing of our 2 nd hypothesis where Org_Trust mediates the relationship between org_justice and org_wellbeing. We removed the other indirect effect between X (org-justice) and Y (org-wellbeing) through org_culture. Here the path $\mathrm{A}$ (from $\mathrm{X}$ to $\mathrm{M}$ i.e. from OJ to ET) is $.23(\mathrm{P}<0.00)$ and the path $\mathrm{B}$ (from $\mathrm{M}$ to Y i.e. ET to EW) is .21 ( $\mathrm{P}<0.001)$ and total indirect effect (Figure 7$)$ is $.048(\mathrm{p}=0.02)$ justifying the mediating role of org-trust between $\mathrm{X}$ and $\mathrm{Y}$.

Figure 9 depicts the testing of our 3rd hypothesis where Org_Trust mediates the relationship between CSR and Org_performance. Here too we deleted the other indirect effect between $\mathrm{X}$ and $\mathrm{Y}$ through org_culture to find out the hypothesized relation. Here the path $\mathrm{A}$ (from $\mathrm{X}$ to $\mathrm{M}$ ) is $.24(\mathrm{P}<0.00)$ and the path $\mathrm{B}$ (from $\mathrm{M}$ to $\mathrm{Y})$ is $.21(\mathrm{P}<0.001)$ and total indirect effect (see table 12$)$ is $.05(\mathrm{P}=0.006)$ justifying the mediating role of org-trust between X and Y (Table 12 ). 


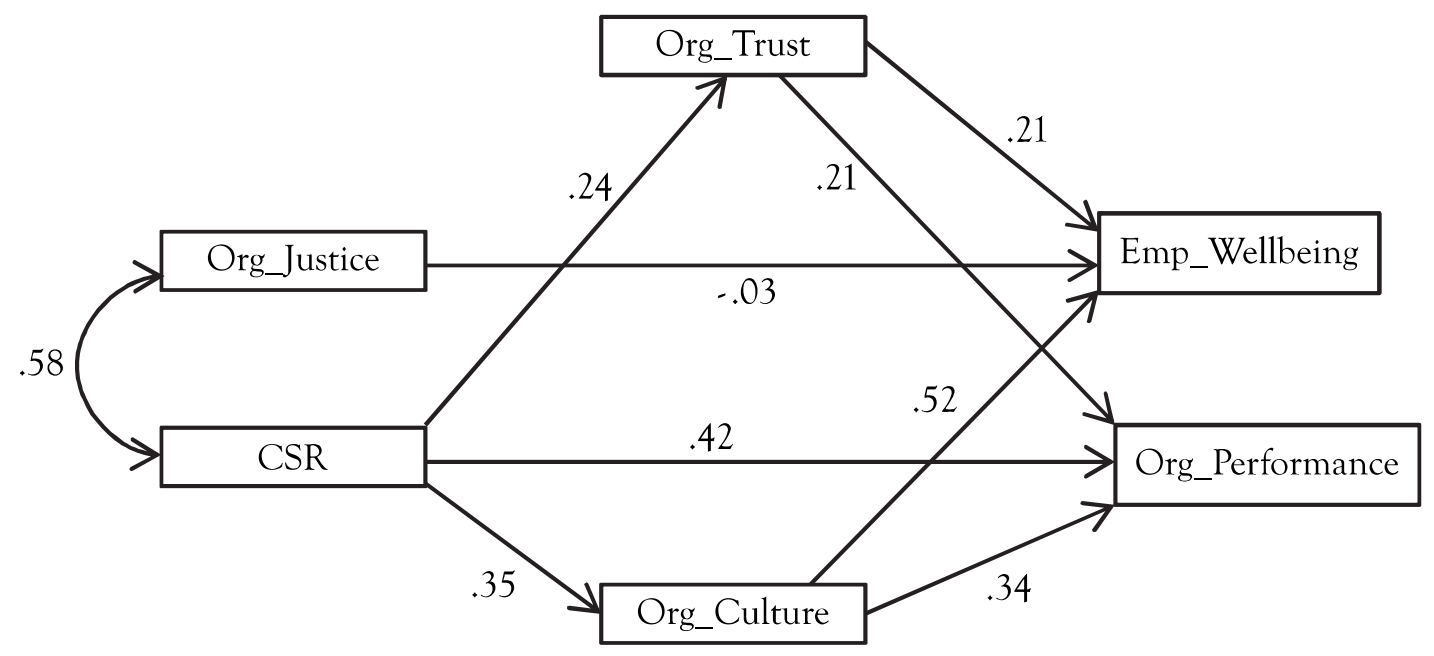

Figure 8: Testing Hypothesis Org_Trust Mediates the Relationship Between Org_Justice and Emp_Wellbeing

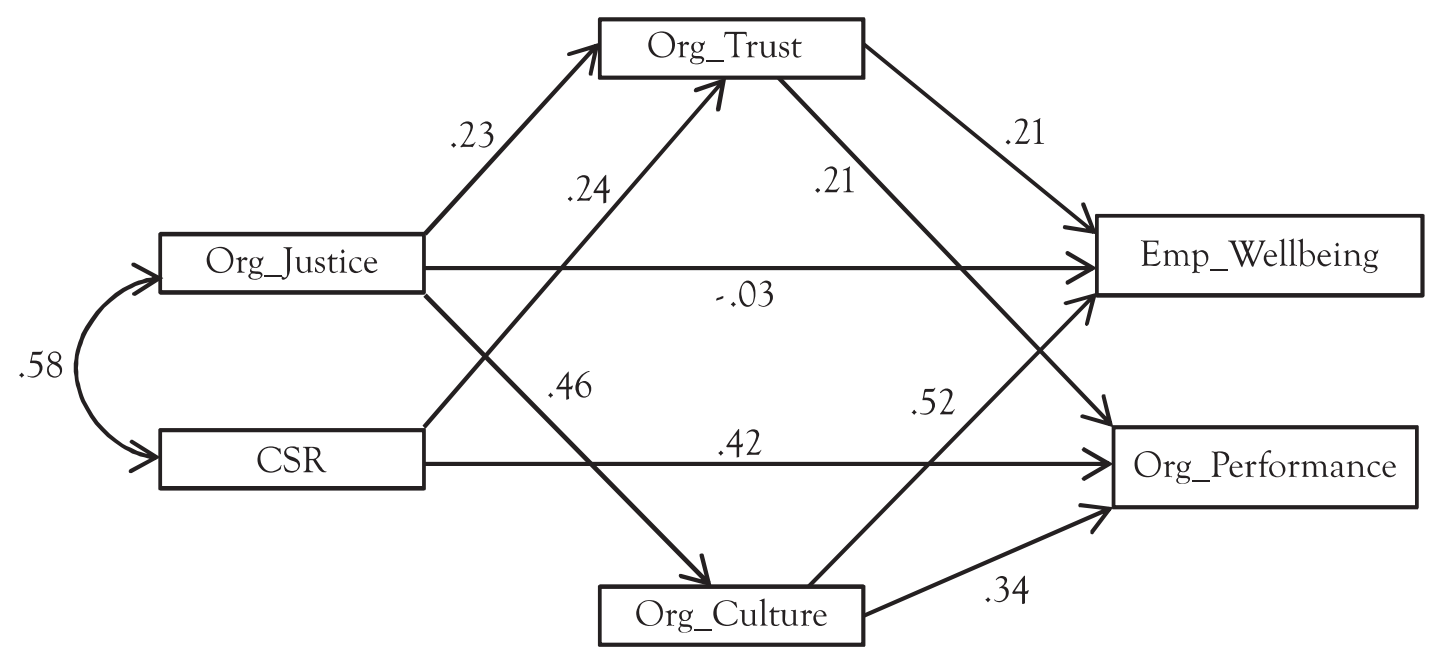

Figure 9: Testing Hypothesis Org_Trust Mediates the Relationship Between CSR and Org_Performance

Figure 10 depicts a model for testing of our 4th hypothesis where org_culture mediates the relationship between CSR and Org_performance. Here too, we removed the other indirect effect between $\mathrm{X}$ and $\mathrm{Y}$ through Org_Trust to find out the hypothesized relation. Here the path $A$ (from X to $M$ ) is .13 ( $p=.12)$. This non-significant path $A$ violates the basic assumption of the mediation analysis so we cannot further proceed to carry out the mediation test. Hence, we reject the 4th hypothesis and conclude that org-culture does not mediate (significantly) between CSR and the org-performance.

\subsection{Comparison of the three methods}

In order to compare results of all three major methods of mediation analysis (i.e. 


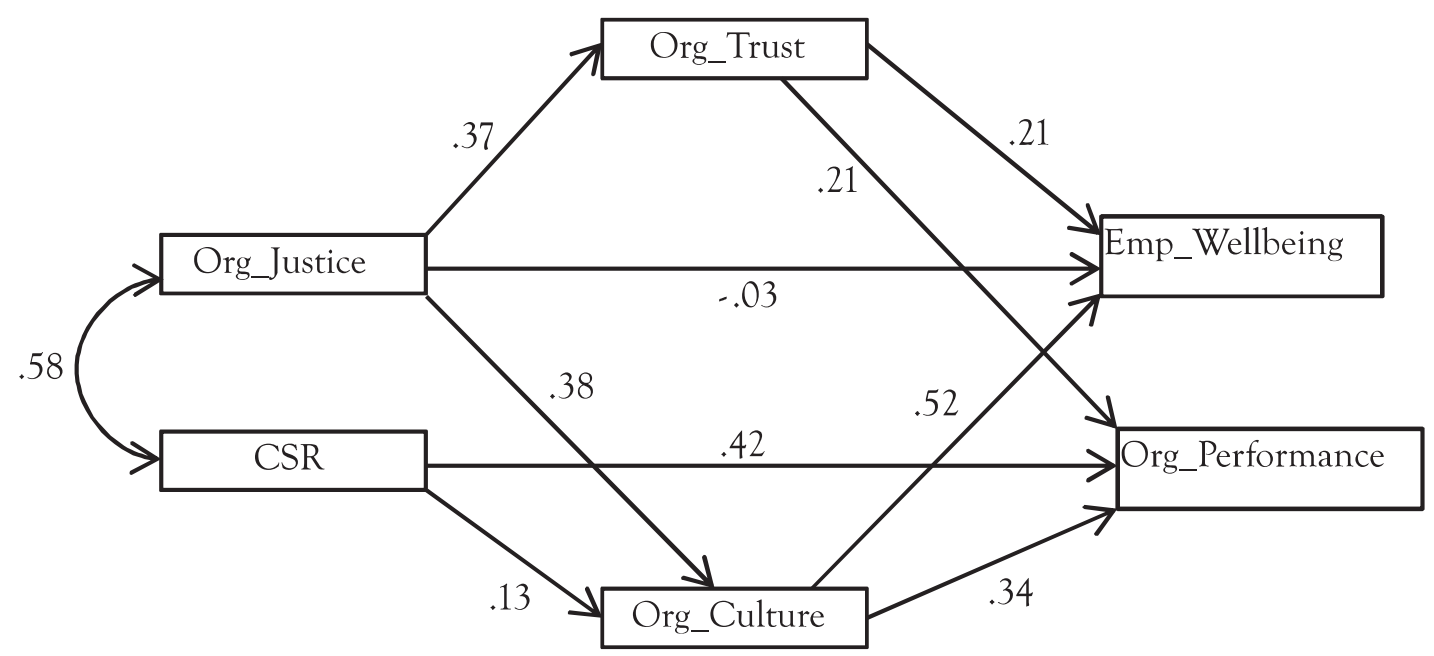

Figure 10: Testing Hypothesis Org_Culture Mediates the Relationship Between CSR and Org_Performance

Baron and Kenny, Bootstrapping and Sobel), we present results of all four hypotheses by using three methods of testing mediation in Table 12. Figure 11 depicts the unstandardized beta weights of all relations which we can use to test the indirect effects manually for Sobel test calculator.

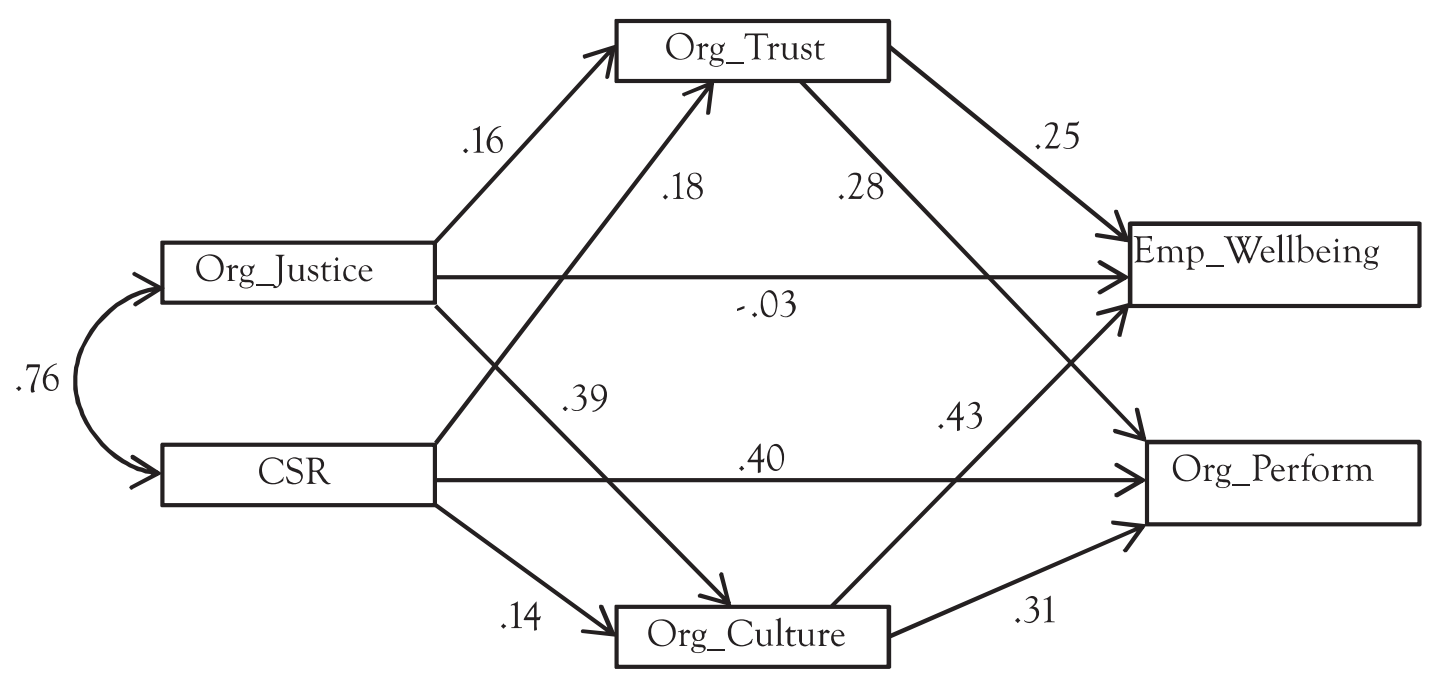

Figure 11: Unstandardized Beta Weights for Sobel Test Calculator

\subsection{Serial/sequential mediation}

Serial or sequential mediation involves a situation where variables affect one another in a chain. As depicted in Figure 12, org _ justice affects Org_Trust, which in turn affects emp_wellbeing, and which eventually affects org_performance. 


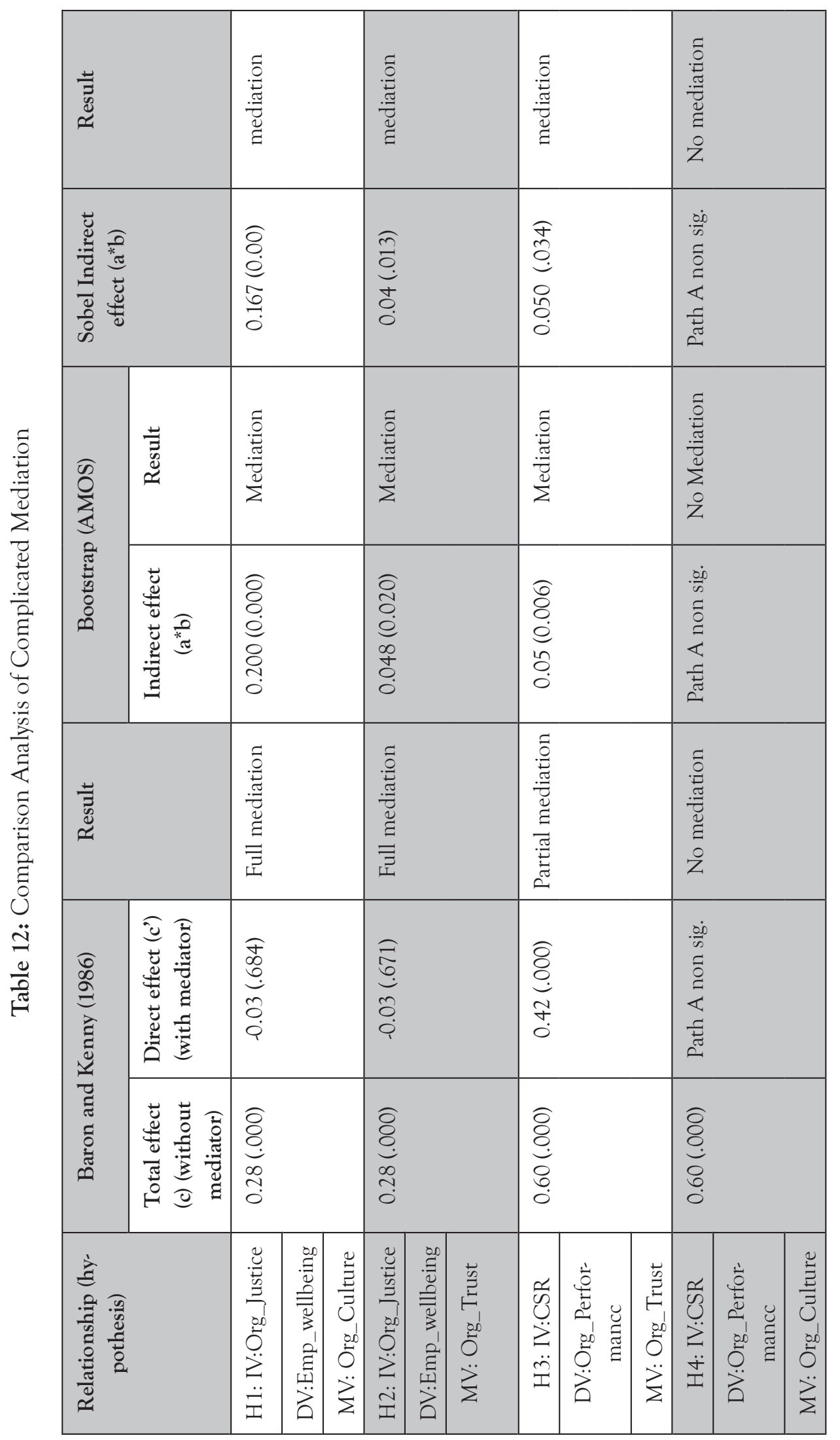




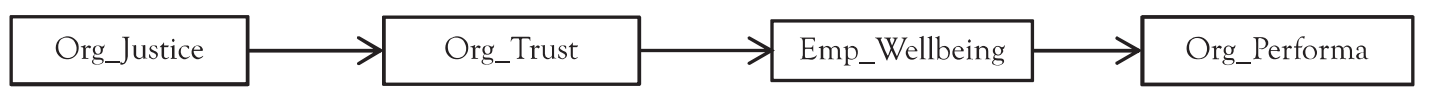

Figure 12: Conceptual Diagram of Serial Mediation.

Figure 13 is the statistical diagram of the same serial relation. A careful analysis of this serial relationship identifies at least five mediation hypotheses, which include:

1. Org_Trust mediates the relationship between Org_justice and emp_wellbeing.

2. Emp_wellbeing mediates the relationship between Org_Trust and org performance.

3. Org_Trust mediates the relationship between org_justice and org_performance.

4. Emp-wellbeing mediates the relationship between org_justice and org_performance.

5. Org_Trust and emp_wellbeing both mediate the relationship between org_justice and org_performance.

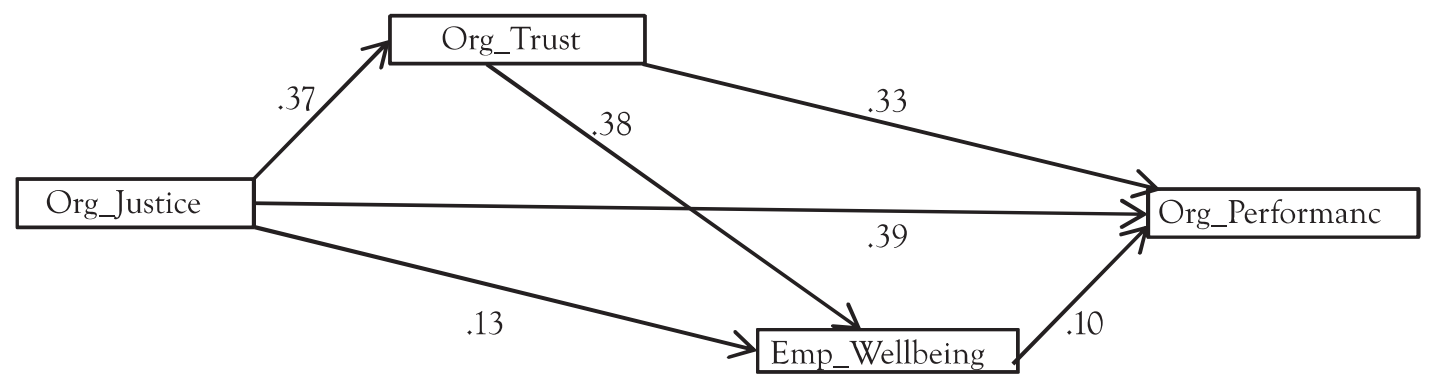

Figure 13: Statistical Diagram and Results of Serial Mediation

Table 13 numerically elaborates the 1st, 2 nd and 5th hypotheses along with a comparison between Baron and Kenney (1986) and Bootstrapping techniques. For testing the hypothesis 3 and 4, we will have to remove the redundant indirect relationship between $\mathrm{X}$ and $\mathrm{Y}$ to test the hypothesized indirect relationship. Detailed numerical results are given in Table 13. 


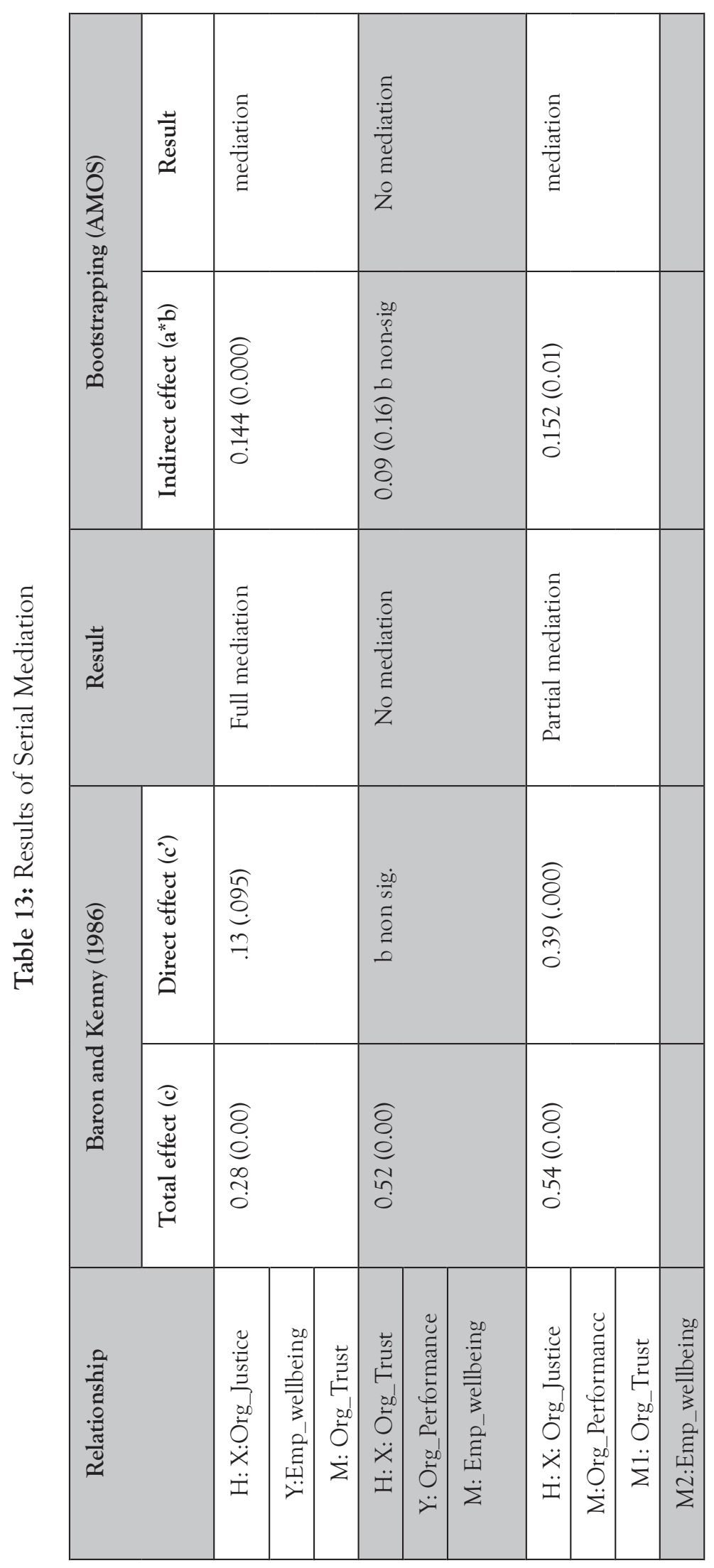




\section{Conclusion}

Baron and Kenny (1986) method should be used with great caution. Researchers must ensure that the data under investigation possesses necessary properties i.e. it meets all basic assumptions of regression analysis. Mediation test is run step-by-step. If at any of the first three steps, relationship is found insignificant, then there is no need to proceed further. Baron and Kenny (1986) method is simple to use. However, it does not indicate whether the indirect effect is statistically significant. This short coming can be addressed by the Sobel test. Sobel test has the capability to produce statistical significance of the indirect effect. One additional advantage of the Sobel test is that it can be used even when raw data is not available and the researcher has only beta coefficients of X-M and M-Y relationships and their standard errors. Besides, it also does not require any exclusive statistical package/application. It can be run by using an online calculator. However, both Baron and Kenny (1986) method and Sobel test are weak in power and type-I error.

Bootstrapping technique has an advantage which is not associated with either Baron and Kenny (1986) method or with Sobel test. However, it is available with Bootstrapping Confidence Interval method which involves the use of PROCESS an adds-on application that runs in SPSS. Besides, it has high statistical power and better control on type-I error. It is also worth-mentioning that it produces better results even when data lacks the property of normal distribution. While interpreting the results, the researchers need to closely look at the BootLLCI and BootULCI values and at the results of Normal theory tests. One weakness of the PROCESS is that it operates within the options available in the form of 72 pre-defined models. If there arises a situation that is outside the scope of these 72 models, the PROCESS simply turns out to be useless.

This weakness of the PROCESS is overcome by the Mediation with bootstrap technique of indirect effect (ab) using AMOS (or some other SEM statistical analysis softwares). It involves the use of covariance-based SEM (CB-SEM). Its only shortcoming is that it can produce misleading results if data lacks the properties of normal distribution and/or if sample size is small. In such situations, researchers are suggested to use partial least square based SEM (PLS-SEM). It should also be noted that complex mediation requires the use of SEM.

\section{Limitations}

The current study does not take into account all methods of mediation analysis. It has covered only three important and commonly used methods. Second limitation is that we have used only continuous variables as independent variables in the current 
study. Mediation analysis using dichotomous or multicategorical types of independent variables (such as two or more experimental conditions) as discussed in Hayes and Preacher (2014) using Mplus or SAS software are not covered by this study. Further we have considered three major conditions of mediating relations i.e. simple, parallel, and serial/sequential. Testing mediation relations at multilevel as discussed by Preacher, Zyphur and Zhang (2010) and Zhang, Zyphur and Preacher (2009) is also beyond the scope of the current study. Moreover, PLS based approaches to mediation are also out of the scope of this article. Future studies may attend to these weaknesses.

\section{References}

Baron, R. M. \& Kenny, D. A. (1986). The moderator-mediator variable distinction in social psychological research: Conceptual, strategic, and statistical considerations. Journal of Personality and Social Psychology, 51(6), 1173-1182.

Bennett, J. A. (2000). Mediator and moderator variables in nursing research: Conceptual and statistical differences. Research in Nursing $\mathcal{E}$ Health, 23(5), 415-420.

Cao, Y. \& Xiang, Y. (2012). The impact of knowledge governance on knowledge sharing. Management Decision, 50(4), 591-610.

Chen, S. Y., Wu, W. C., Chang, C. S., Lin, C. T., Kung, J. Y., Weng, H. C.,... Lee, S. I. (2015). Organizational justice, trust, and identification and their effects on organizational commitment in hospital nursing staff. BMC Health Services Research, 15(1), 1-17.

Choi, Y. Y. (2014). Corporate social responsibility and firm performance through the mediating effect of organizational trust in Chinese firms. Chinese Management Studies, 8(4), 577-592.

Da Silveira, G. J. C. \& Arkader, R. (2007). The direct and mediated relationships between supply chain coordination investments and delivery performance. International Journal of Operations and Production Management, 27(2), 140-158.

Hayes, A. F. (2009). Beyond Baron and Kenny: Statistical mediation analysis in the new millennium. Communication Monographs, 76(4), 408-420.

Hayes, A. F. (2013). Introduction to mediation, moderation, and conditional analysis. New York, NY: The Guilford Press.

Hayes, A. F. (2012). PROCESS: A versatile computational tool for observed variable mediation, moderation, and conditional process modeling [White paper]. Retrieved from http://www.afhayes. com/public/process2012.pdf

Hayes, A. F. \& Preacher, K. J. (2014). Statistical mediation analysis with a multicategorical independent variable. British Journal of Mathematical and Statistical Psychology, 67(3), 451-470.

Hertzog, M. (2018). Trends in mediation analysis in nursing research: Improving current practice. Western 
Journal of Nursing Research, 40(6), 907-930.

Hussey, D. M. \& Eagan, P. D. (2007). Using structural equation modeling to test environmental performance in small and medium-sized manufacturers: Can SEM help SMEs? Journal of Cleaner Production, 15(4), 303-312.

Lucia-Palacios, L., Bordonaba-Juste, V., Polo-Redondo, Y., \& Grunhagen, M. (2014). E-Business implementation and performance: Analysis of mediating factors. Internet Research, 24(2), 223-245.

MacKinnon, D. P., \& Dwyer, J. H. (1993). Estimating mediated effects in prevention studies. Evaluation Review, 17(2), 144-158.

MacKinnon, D. P., Fairchild, A. J., \& Fritz, M. S. (2007). Mediation analysis. Annual Review of Psychology, 58(1), 593-614.

MacKinnon, D. P., Lockwood, C. M., Hoffman, J. M., West, S. G., \& Sheets, V. (2002). A comparison of methods to test mediation and other intervening variable effects. Psychological Methods, 7(1), 83-104.

MacKinnon, D. P., Warsi, G., \& Dwyer, J. H. (1995). A simulation study of mediated effect measures. Multivariate Behavioral Research, 30(1), 41-62.

Preacher, K. J. \& Hayes, A. F. (2008). Asymptotic and resampling strategies for assessing and comparing indirect effects in multiple mediator models. Behavior Research Methods, 40 (3), 879-891.

Preacher, K. J., Rucker, D. D., \& Hayes, A. F. (2007). Addressing moderated mediation hypotheses: Theory, methods, and prescriptions. Multivariate Behavioral Research, 42(1), 185-227.

Preacher, K. J., Zyphur, M. J., \& Zhang, Z. (2010). A general multilevel SEM framework for assessing multilevel mediation. Psychological Methods, 15(3), 209-233.

Roberts, G., Scammacca, N., \& Roberts, G. J. (2018). Causal mediation in educational intervention studies. Behavioral Disorders, 43(4), 457-465.

Rucker, D. D., Preacher, K. J., Tormala, Z. L., \& Petty, R. E. (2011). Mediation analysis in social psychology: Current practices and new recommendations. Social and Personality Psychology Compass, 5(6), 359-371.

Sanders, N. R. (2007). An empirical study of the impact of e-business technologies on organizational collaboration and performance. Journal of Operations Management, 25(6), 1332-1347.

Shaver, J. M. (2005). Testing for mediating variables in management research: Concerns, implications, and alternative strategies. Journal of Management, 31(3), 330-353.

Shrout, P. E., \& Bolger, N. (2002). Mediation in experimental and nonexperimental studies: New procedures and recommendations. Psychological Methods, 7(4), 422-445.]

Sobel, M. E. (1982). Asymptotic confidence intervals for indirect effects in structural equations models. In S. Leinhardt (Ed.), Sociological methodology. (pp. 290-312). San Francisco, CA: Jossey-Bass.

Stone-Romero, E. F. \& Rosopa, P. J. (2004). Inference problems with hierarchical multiple regression-based 
tests of mediating effects. Research in Personnel and Human Resources Management, 23, 249-290.

Tate, C. U. (2015) On the overuse and misuse of mediation analysis: It may be a matter of timing. Basic and Applied Social Psychology, 37(4), 235-246.

Yu, Y. \& Choi, Y. (2014). Corporate social responsibility and firm performance through the mediating effect of organizational trust in Chinese firms. Chinese Management Studies, 8(4), 577-592.

Zhang, Z., Zyphur, M. J., \& Preacher, K. J. (2009). Testing multilevel mediation using hierarchical linear models: Problems and solutions. Organizational Research Methods, 12(4), 695-719.

Zhao, X., Lynch Jr, J. G., \& Chen, Q. (2010). Reconsidering Baron and Kenny: Myths and truths about mediation analysis. Journal of Consumer Research, 37(2), 197-206. 